\title{
Salicylaldimine Copper(II) complex catalyst: Pioneer for ring opening Polymerization of Lactide
}

\author{
ANITA ROUTARAY ${ }^{\mathrm{a}}$, NIBEDITA NATH ${ }^{\mathrm{a}}$, TUNGABIDYA MAHARANA ${ }^{\mathrm{b}, *}$, \\ PRATAP KUMAR SAHOO ${ }^{c}$, JAYA PRAKASH DAS ${ }^{\mathrm{a}}$ and ALEKHA KUMAR SUTAR ${ }^{\mathrm{a}, *}$ \\ ${ }^{a}$ Catalysis Research Lab, Department of Chemistry, Ravenshaw University, Cuttack, Odisha, 753 003, India \\ ${ }^{b}$ Department of Chemistry, National Institute of Technology, Raipur, 492 010, India \\ ${ }^{\mathrm{c}}$ School of Physical Sciences, National Institute of Science Education and Research, Bhubaneswar, Odisha, \\ 751005 , India \\ e-mail: mtungabidya@gmail.com; dralekhasutar@gmail.com
}

MS received 25 November 2015; revised 28 March 2016; accepted 3 April 2016

\begin{abstract}
Salicylaldimine copper complex has been synthesized and its reactivity for the ring-opening polymerization (ROP) of lactide has been studied. This monomeric copper complex was prepared by the reaction of copper(II) solution with one molar equivalent of salicylaldimine Schiff-base ligand in methanol under nitrogen atmosphere. This copper complex has been characterized by different spectroscopic methods, which showed square planar geometry. The molecular structure of the salicylaldimine Schiff-base has been determined by $\mathrm{X}$-ray diffraction studies. The complex was tested as the initiator for the ring-opening polymerization of lactide, with variation in diamine group in ligand. The rate of polymerization is dependent on the diamine group in the following order: ethylene $>$ propylene $>$ phenyl. The salicylaldimine copper complex allows controlled ring-opening polymerization as indicated by the linear relationship between the percentage conversion and the number-average molecular weight. On the basis of literature reports, a mechanism for ROP of lactide has been proposed.
\end{abstract}

Keywords. Ring opening polymerization (ROP); lactide; salicylaldimine; copper complex; PLA.

\section{Introduction}

Poly(lactic acid) (PLA), ${ }^{1-3}$ produced by the ringopening polymerization (ROP) of lactide (LA), is a leading biodegradable and biocompatible polyester and PLA degrades to form nontoxic components (water and carbon dioxide), which makes PLA very useful for biomedical and pharmaceutical applications. ${ }^{4-7}$ Due to their outstanding mechanical properties, PLAs are used in surgery as orthopedic applications, tissue engineering and biodegradable internal fixation devices. ${ }^{8,9}$

The preventive use in biomedical application is dependent on the extent to which the metal residues are removable upon quenching the polymerization. As removal of metal can never be complete, a preferred and feasible industrial process should employ metals in which the residues are not cytotoxic. It is practical to use environmentally benign metals so that there will be no harm due to metal residue in polymers. ${ }^{10}$ Different metal initiators or catalysts have been used in the formation of PLA, such as compounds of aluminum, ${ }^{11-13}$ lithium, ${ }^{1,14-16}$ magnesium, ${ }^{17-23}$ iron, ${ }^{24}$

*For correspondence tin, ${ }^{25,26}$ titanium, ${ }^{27,28}$ or zinc. ${ }^{19,29-33}$ Recently, initiators or catalysts based on metal such as $\mathrm{Ca}, \mathrm{Mg}$, Fe and $\mathrm{Zn}$ have received great interest because of their metabolized activity in the body. ${ }^{34}$ Comparatively, copper complexes with high electron transfer ability, moderate Lewis acidity and stability associated with reactive intermediates, should be the topic of in depth investigations. Copper is a biocompatible metal supporting the survival of life and to the best of our knowledge there have been few reports on copper initiators having nitrogen-containing polydentate ligands (which appear as one of the most versatile ligand classes in both main group and transition metal coordination chemistry as these allow facile modulation of steric and electronic factors ${ }^{35}$ ) and their application in ROP of lactide. These include copper complexes derived from pyrazole, ${ }^{36}$ phenoxy-ketimine, ${ }^{37}$ salicylaldimine, ${ }^{38}$ and diketiminate, ${ }^{39}$ which are active towards polymerization of lactides and produce polymer with moderate number average molecular weights and narrow molecular weight distribution. Nowadays, all the commercial PLAs are synthesized using FDA-approved stannous octanoate as catalyst. Copper acetate having same 
catalytic characteristics as stannous octanoate and less toxic has been used for synthesis of PLA. ${ }^{40}$

Recently, John et al., showed that phenoxy-ketimine copper complexes 1-3 shown in figure 1 successfully catalyzed the ROP of $L$-lactide under solvent-free conditions at $160-180^{\circ} \mathrm{C}$, producing PLLA of moderate molecular weights $\left(M_{n}=8000-11000,[\mathrm{M}]:[\mathrm{I}]=50\right)$ with $70-80 \%$ conversion. ${ }^{37}$

Appavoo et al., investigated the ROP of $D L$-lactide using copper complexes 4-7 with pyrazole unit to produce low molecular weight polymers. ${ }^{36}$ They reported that the complex 4 (figure 1) displayed relatively higher catalytic conversion than other complexes 5-7 at $110^{\circ} \mathrm{C}$ after $144 \mathrm{~h}$ (monomer: initiator $=100: 1)$. And also, Bhunora et al., investigated ROP of $D L$-lactide using four coordinate copper complexes 8-10 (figure 1) and showed highest conversion (80\%) in case of complex $\mathbf{1 0}$ rather than $8(55 \%)$ and $9(18 \%)$ (monomer to initiator ratio $=50){ }^{38}$

The relative success of tetra-coordinate salicylaldimine complexes in various polymerization reactions is most probably due to the scope for suitable alteration of the steric bulk and the electronic property of the subsidiary ligand and also due to their easy synthetic accessibility, as the salicylaldimines are generally prepared via Schiff base condensation reactions. Despite extensive utility of salicylaldimine Schiff base complexes in many important chemical transformations, ${ }^{35}$ their application in ROP of $L$-lactide largely remains unexplored. Because of the relative scarcity of reports on the use of copper complexes as ROP initiators, we embarked on a study of these complexes in such processes. Here we report the synthesis and use of tetra-coordinated salicylaldimine copper complex in $L$-lactide polymerization. This complex is stable in air and easy to prepare. In addition, the steric and electronic effects of ligands on polymerization activity were also investigated. A kinetic study of the ROP of $L$-lactide was carried out and correlated with the nature of the ligands. In addition, a mechanism for ROP of lactide has been proposed.

\section{Experimental}

\subsection{Materials}

Syntheses were performed under a dry nitrogen atmosphere using a combination of a glove box and standard Schlenk techniques. All solvents were of analytical grade and were dried and distilled prior to use. Toluene and dichloromethane were dried and distilled from sodium benzophenone and $\mathrm{P}_{2} \mathrm{O}_{5}$, respectively. Anhydrous copper chloride, Ethylene diamine (ED), propylene diamine (PD) and benzene-1, 2-diamine (BD) were purchased from HiMedia Laboratories Pvt. Ltd., Mumbai, India and 2-hydroxy-3-methoxybenzaldehyde (HMB) and benzyl alcohol $(\mathrm{BnOH})$ were procured from E. Merck, India. $L$-Lactide (LA) purchased from Sigma-Aldrich was used as received. Other chemicals were of analytical grade (>99.0 wt \%) and used as received.

\subsection{Characterization of the Schiff bases and its copper complex}

IR spectra were recorded on $\mathrm{KBr}$ pellet using PerkinElmer 1600 FTIR Spectrophotometer. The electronic spectra were recorded with Shimadzu 1601 PC UVVis Spectrophotometer. TGA was carried out by using Perkin-Elmer Pyris, Diamond Thermal Analyzer under nitrogen atmosphere at a heating rate of $10^{\circ} \mathrm{C} \mathrm{min}^{-1}$. AAS was done by Perkin-Elmer 3100 Atomic Absorption Spectrometer at $\lambda_{\max }$ of copper ion. Haraeus Carlo Ebra 1108 Elemental Analyzer was used for

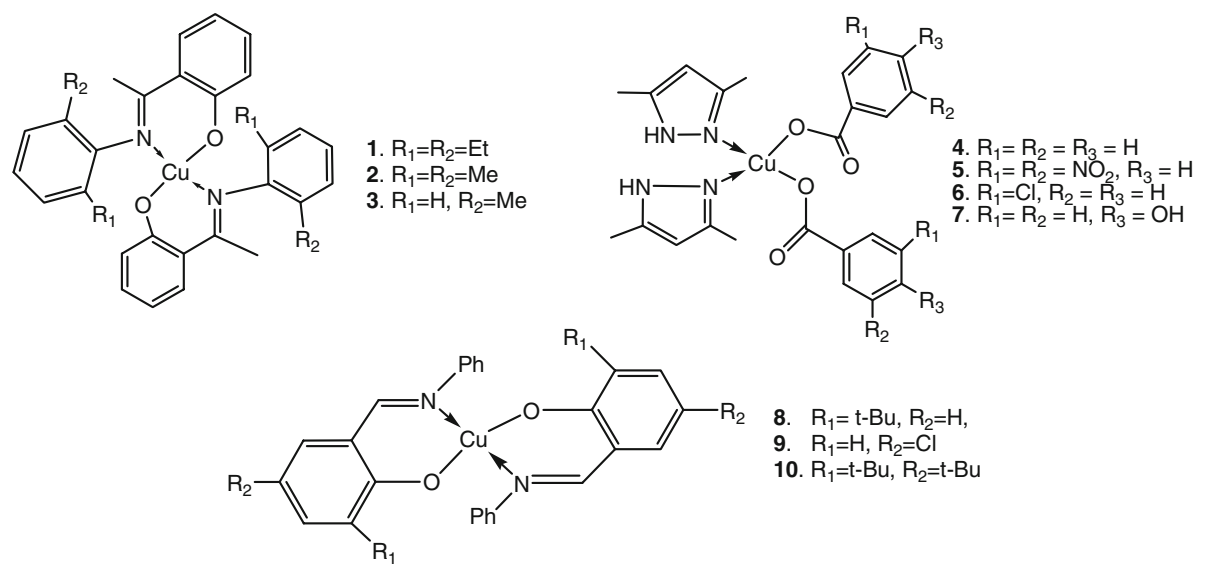

Figure 1. Copper complexes used for ROP of $L$-lactide. ${ }^{36-38}$ 
analyzing the composition of Schiff bases and its copper complexes. The NMR spectra were recorded on an FT-NMR-Bruker $300 \mathrm{MHz}$ Spectrometer using DMSO- $\mathrm{d}^{6}$ as a solvent and tetramethylsilane (TMS) as an internal reference. The magnetic moment $(\mu)$ of metal complexes was measured using Vibrating Sample Magnetometer-155. The molecular weight of Schiff base its copper complex and PLA were determined using a Vapor Pressure Osmometer (Merck VAPRO 5600 , Germany). A suitable crystal of ligand was analyzed by Bruker Kappa Apex-II diffractometer.

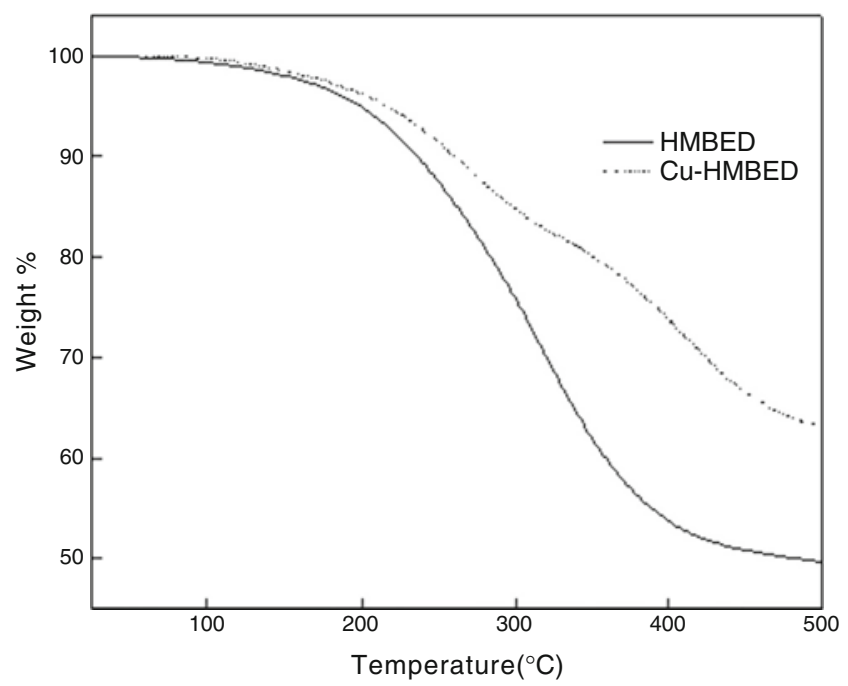

Figure 2. Thermal stability of the H2MBED Schiff base and its copper complex.

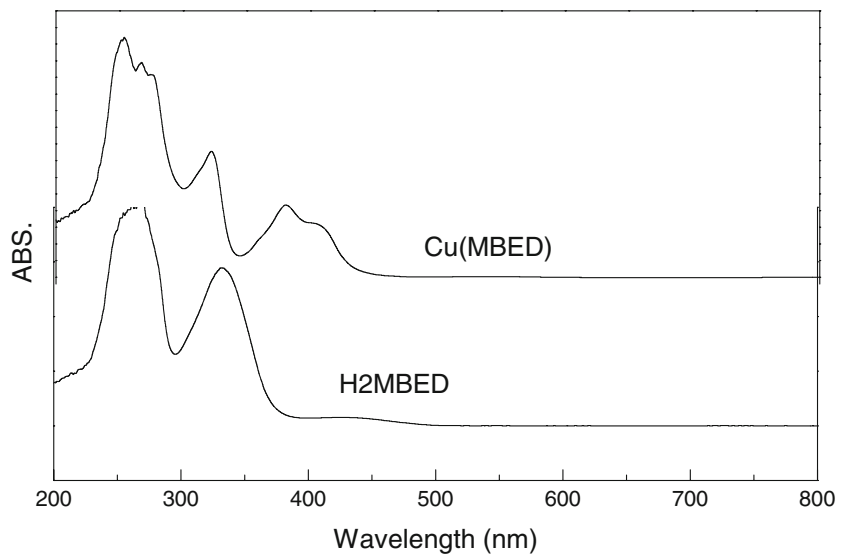

Figure 3. Electronic spectra of H2MBED Schiff base $(0.05 \mathrm{mM})$ and its copper complex $(0.05 \mathrm{mM})$.

\subsection{Synthesis of Characterization of H2MBED Schiff base and its copper complexes}

$\mathrm{N}, \mathrm{N}^{\prime}$-bis (2-hydroxy-3-methoxy benzaldehyde) ethylenediamine (H2MBED) Schiff base was synthesized by the modified synthetic route reported earlier. ${ }^{41}$ The mixture of 2-hydroxy-3-methoxybenzaldehyde (20.00 $\mathrm{mmol}, 3.04 \mathrm{~g})$ and ethylene diamine $(10.00 \mathrm{mmol}, 0.6 \mathrm{~g})$ in methanol was refluxed at $60^{\circ} \mathrm{C}$ for about $2 \mathrm{~h}$. The straw yellow colored crystals were obtained on cooling the reaction mixture, and then they were recrystallized with chloroform. The copper complex $\mathrm{Cu}(\mathrm{MBED})$ was synthesized by refluxing $100 \mathrm{~mL}$ methanolic solution of Schiff base $(20.00 \mathrm{mmol}, 6.56 \mathrm{~g})$ and copper chloride $(20.00 \mathrm{mmol}, 2.69 \mathrm{~g})$ in a round bottom flask at $60^{\circ} \mathrm{C}$ for $7 \mathrm{~h}$. All reactions were performed under nitrogen atmosphere. Finally, the copper complex was recrystallized in methanol and dried in a vacuum desiccator.

The thermal stability of the $\mathrm{Cu}(\mathrm{MBED})$ catalyst was analyzed for their application in high-temperature reactions and to provide proof for the complexation of copper ion with H2MBED Schiff base. The TGA of H2MBED Schiff base showed a weight loss of $50.4 \mathrm{wt} \%$ at $500^{\circ} \mathrm{C}$, but its copper(II) chloride complex showed a weight loss of $37.0 \mathrm{wt} \%$, which indicates that $\mathrm{Cu}$ (MBED) complex was more stable ${ }^{42}$ in comparison to ligand (figure 2). In addition to thermal analysis, FTIR and UV techniques were used for H2MBED Schiff base and its copper complex to provide evidence for the formation of $\mathrm{Cu}(\mathrm{MBED})$. Elemental analysis and magnetic property of the copper complex confirmed the structures and geometries.

The H2MBED Schiff base has absorption bands at $1613 \mathrm{~cm}^{-1}$ and $1256 \mathrm{~cm}^{-1}$ for $>\mathrm{C}=\mathrm{N}$ and phenolic $>\mathrm{C}-\mathrm{O}$, respectively, and a broad band between 3100 and $2800 \mathrm{~cm}^{-1}$ was observed for phenolic $\mathrm{OH}$ (figure $\mathrm{S} 1$ in Supplementary Information). From elemental analysis of H2MBED Schiff base, it was observed that (wt \%): $\mathrm{C}=66.13, \mathrm{~N}=8.42$ and $\mathrm{H}=6.21$; and the Calcd (\%): $\mathrm{C}=65.84, \mathrm{~N}=8.53$ and $\mathrm{H}=$ 6.14, which corresponded to the formula $\mathrm{C}_{18} \mathrm{H}_{20} \mathrm{~N}_{2} \mathrm{O}_{4}{ }^{41}$ The molecular weight of H2MBED was $329.23 \mathrm{~g} \mathrm{~mol}^{-1}$ (Calcd. $328.36 \mathrm{~g} \mathrm{~mol}^{-1}$ ). The UV-Vis absorption bands at $264 \mathrm{~nm}$ and $330 \mathrm{~nm}$ of H2MBED (figure 3), represent the transitions $\pi \rightarrow \pi^{*}$ and $n \rightarrow \pi^{*}$, respectively.

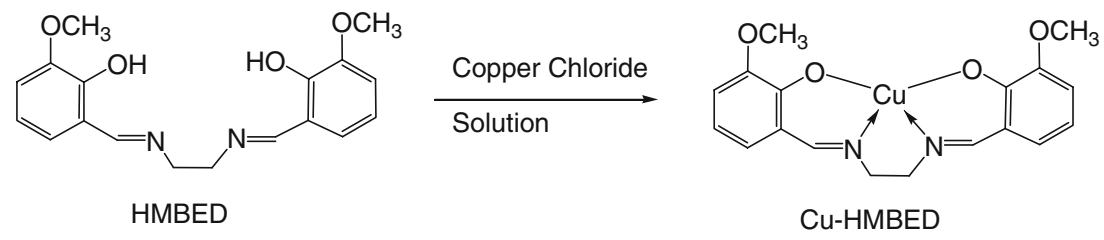

Scheme 1. Preparation of copper(II) complex of H2MBED Schiff base. 
The copper(II) complex of H2MBED Schiff base was prepared by refluxing the mixture of Schiff base and copper(II) chloride at $60^{\circ} \mathrm{C}$ for $7 \mathrm{~h}$ (scheme 1) in methanol. It was observed that complexation of copper(II) ion was $83.8 \mathrm{wt} \%$. The elemental analysis of $\mathrm{Cu}(\mathrm{MBED})$ complex showed (wt \%): $\mathrm{C}=$ 56.39, $\mathrm{N}=7.13$ and $\mathrm{H}=4.62$; Calcd. (\%): $\mathrm{C}=$ 55.45, $\mathrm{N}=7.18$ and $\mathrm{H}=4.65$, which corresponds to the formula $\mathrm{C}_{18} \mathrm{H}_{18} \mathrm{CuN}_{2} \mathrm{O}_{4}$. The observed molecular weight of $\mathrm{Cu}(\mathrm{MBED})$ was $390.46 \mathrm{~g} \mathrm{~mol}^{-1}$ (Calcd. $389.89 \mathrm{~g} \mathrm{~mol}^{-1}$ ).

Due to the formation of copper complex, there was a considerable difference in IR bands for $>\mathrm{C}=\mathrm{N}$ and $>\mathrm{C}-\mathrm{O}$ groups and also two new absorption bands at $566 \mathrm{~cm}^{-1}$ and $442 \mathrm{~cm}^{-1}$ appeared due to the formation of $\mathrm{Cu}-\mathrm{O}$ and $\mathrm{Cu}-\mathrm{N}$ bonds in $\mathrm{Cu}(\mathrm{MBED})$ complex (table S1 in SI and figure 4). And also, vanishing of phenolic $\mathrm{OH}$ band between 2800 and $3000 \mathrm{~cm}^{-1}$ of H2MBED confirms the formation of $\mathrm{Cu}$ (MBED). ${ }^{41}$

The formation of $\mathrm{Cu}$ (MBED) showed hypsochromic shift in $\pi \rightarrow \pi^{*}$ transition from $264 \mathrm{~nm}$ to $254 \mathrm{~nm}$, and for the $\mathrm{n} \rightarrow \pi^{*}$ transition from $330 \mathrm{~nm}$ to $269 \mathrm{~nm}$

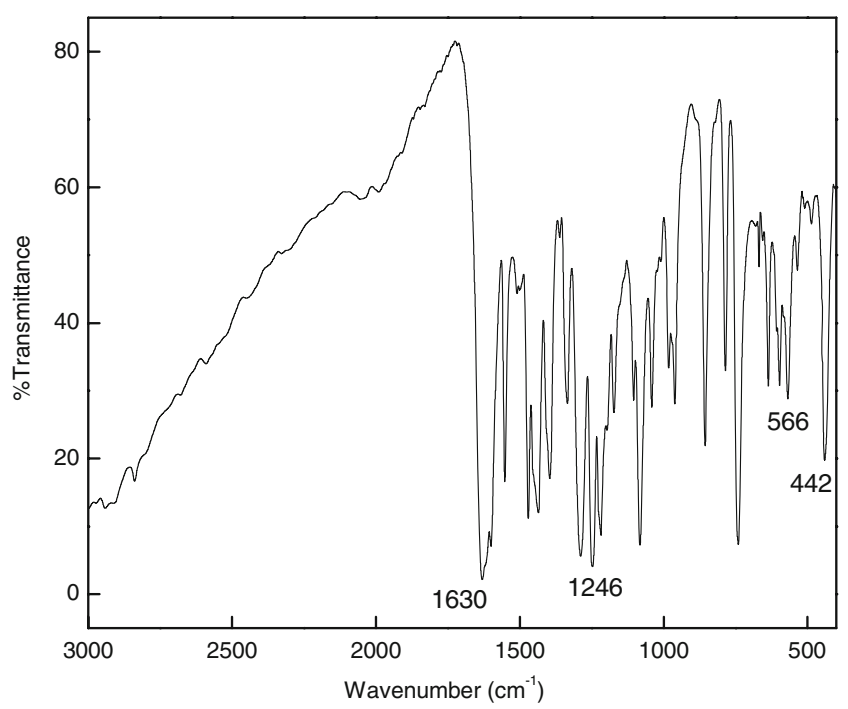

Figure 4. FTIR spectrum of $\mathrm{Cu}(\mathrm{MBED})$ complex. (table $\mathrm{S} 1 \mathrm{in} \mathrm{SI}$ ). And also showed transitions at $322 \mathrm{~nm}$ and $383 \mathrm{~nm}$ for $\mathrm{C} \rightarrow \mathrm{T}$ and $\mathrm{d} \rightarrow \mathrm{d}$ transition, respectively. These electronic transitions correspond to $t_{2 g}{ }^{6}$ $\mathrm{e}_{\mathrm{g}}^{3}$ configurations for copper(II) ion in this complex. The magnetic moment $(\mu)$ of the $\mathrm{Cu}(\mathrm{MBED})$ complex was found to be $1.84 \mathrm{BM}$, which indicated that it was paramagnetic and square planar structure with $\mathrm{dsp}^{2}$ hybridization.

\subsection{Crystal structure of H2MBED}

X-ray diffraction measurement showed that single crystals of H2MBED belongs to space group Pc and monoclinic system. Crystallographic data and the results of structure refinements are summarized in table S2 (in Supplementary Information) and the crystal structure shown in figure 5. As shown in figure 5, each HMB binds to two nitrogen of BD. Selected bond lengths $(\AA)$ and bond angles (deg) are: $\mathrm{N}(2)-\mathrm{C}(11)$ 1.274(3); $\mathrm{N}(2)-\mathrm{C}(10)$ 1.451(3); C(9)-N(1) 1.452(3); $\mathrm{N}(1)-\mathrm{C}(8) \quad 1.270(3) ; \mathrm{C}(11)-\mathrm{N}(2)-\mathrm{C}(10) \quad 119.56(19) ;$ $\mathrm{N}(2)-\mathrm{C}(11)-\mathrm{C}(12)$ 121.70(19); N(2)-C(11)-H(8) 119.2; $\mathrm{N}(2)-\mathrm{C}(10)-\mathrm{C}(9)$ 110.38(18); $\mathrm{N}(2)-\mathrm{C}(10)-\mathrm{H}(7 \mathrm{~A})$ 109.6; $\mathrm{N}(2)-\mathrm{C}(10)-\mathrm{H}(7 \mathrm{~B})$ 109.6; N(1)-C(9)-C(10) 109.82(18); $\mathrm{N}(1)-\mathrm{C}(9)-\mathrm{H}(6 \mathrm{~B})$ 109.7; N(1)-C(9)-H(6A) 109.7; C(8)$\mathrm{N}(1)-\mathrm{C}(9)$ 119.71(19); N(1)-C(8)-C(6) 123.2(2); N(1)C(8)-H(5) 118.4.

\section{$2.5 \mathrm{Cu}(\mathrm{MBED})$ complex in ring opening polymerization of L-lactide}

A typical polymerization procedure was exemplified by the synthesis of PLA-150 $([\mathrm{LA}] /[\mathrm{Cu}]=150)$ at room temperature. To a rapidly stirred solution of $\mathrm{Cu}(\mathrm{MBED})$ $(0.052 \mathrm{~g}, 0.133 \mathrm{mmol})$ in toluene $(30 \mathrm{~mL})$ was added $L$-lactide ( $2.88 \mathrm{~g}, 20 \mathrm{mmol}$ ) along with requisite amount of benzyl alcohol. A rise in viscosity was observed and finally the stirring was ceased after $25 \mathrm{~h}$. Volatile materials were removed under vacuum, and the residue was

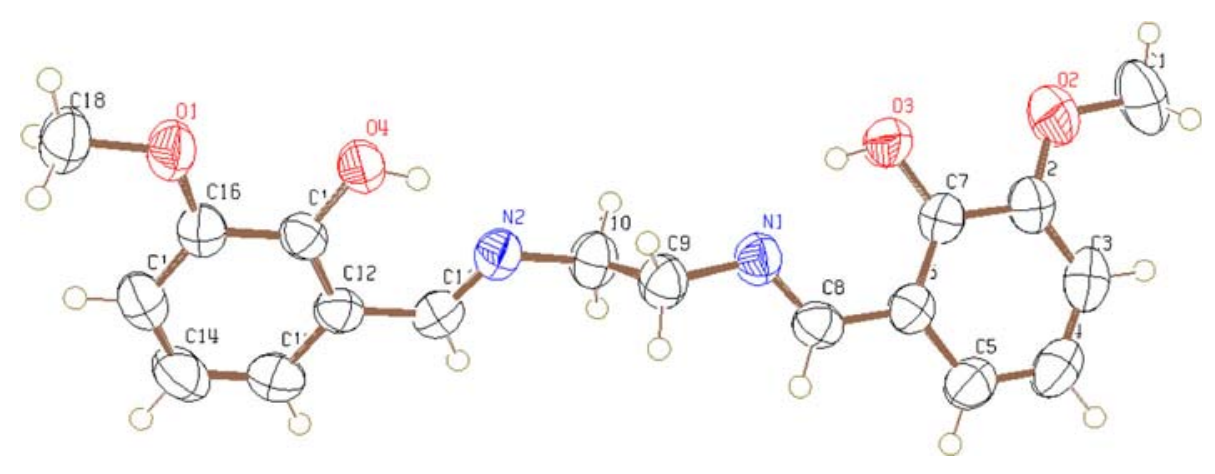

Figure 5. Crystal structure of H2MBED. 
extracted with THF $(30 \mathrm{~mL})$. The extraction was dried again and the white precipitate was washed with nhexane three times and dried under vacuum overnight, giving a crystalline white solid. Yield: $2.4 \mathrm{~g}(83 \%)$.

The molecular weights $\left(M_{n}\right.$ and $\left.M_{w}\right)$ and polydispersity index $\left(M_{w} / M_{n}\right)$ were determined by using gel permeation chromatography (GPC) manufactured by Waters. The GPC instrument was equipped with a Waters 1525 Binary HPLC pump. Two columns, namely, Waters Styragel HR4 7.8×300 mm, "WAT10573" and "WAT044223" were used in series for separation using THF as the solvent and mobile phase. The flow rate of THF was $1.0 \mathrm{~mL} / \mathrm{min}$. An ELS detector, Waters

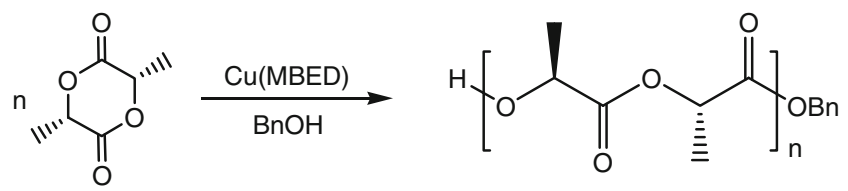

Scheme 2. Polymerization of lactide in presence of benzyl alcohol $(\mathrm{BnOH})$.
2420, was used for detection of different molecular weight fractions. Polystyrene standards with a low dispersity index were used to generate a calibration curve. The GPC chromatograms were analyzed through Breeze version 3.3 software.

\section{Results and Discussion}

\section{1 $\mathrm{Cu}(\mathrm{MBED})$ complex in ring opening polymerization of L-lactide}

On the basis of the 'immortal' property of lactide polymerization demonstrated by several copper complexes ${ }^{36-39}$ and the evidence of in situ formation of metal alkoxide in the presence of alcohol, ${ }^{11-33}$ the complex $\mathrm{Cu}(\mathrm{MBED})$ was expected to behave as catalyst for the ROP of lactide in the presence of benzyl alcohol. The copper complex $\mathrm{Cu}(\mathrm{MBED})$ in presence of benzyl alcohol does initiate the ring-opening polymerization of $L$-lactide (LA) in dichloromethane at $30^{\circ} \mathrm{C}$ (scheme 2). The polymerization results are listed in tables 1 and 2 .

Table 1. Polymerization of $L$-lactide using $\mathrm{Cu}(\mathrm{MBED})$ at $30^{\circ} \mathrm{C}$.

\begin{tabular}{lcccccr}
\hline Entry & Solvent & Conversion $^{\mathrm{a}}(\%)$ & $\mathrm{M}_{\mathrm{n}}\left(\mathrm{Theory}^{\mathrm{b}}\left(\mathrm{g} \mathrm{mol}^{-1}\right)\right.$ & $\mathrm{M}_{\mathrm{n}}(\mathrm{VPO})^{\mathrm{c}}\left(\mathrm{g} \mathrm{mol}^{-1}\right)$ & $\mathrm{M}_{\mathrm{n}}(\mathrm{GPC})^{\mathrm{d}}$ & PDI \\
\hline 1 & $\mathrm{CH}_{2} \mathrm{Cl}_{2}$ & 96.4 & 21000 & 24000 & 23200 & 1.08 \\
2 & Toluene & 81.2 & 17600 & 12500 & 13700 & 1.06 \\
3 & THF & 62.3 & 13500 & 8300 & 7000 & 1.06 \\
\hline
\end{tabular}

Conditions: $[L-\mathrm{LA}]_{0}=20 \mathrm{mmol}$, room temperature, Reaction time $24 \mathrm{~h},[\mathrm{M}]_{0} /[\mathrm{Cu}] /[\mathrm{BnOH}]=150 / 1 / 1$

${ }^{a}$ Percentage conversion of the monomer [(weight of polymer recovered/weight of monomer $) \times 100$ ]

${ }^{\mathrm{b}}$ Calculated by $\left[\left([\mathrm{LA}]_{0} /[\mathrm{BnOH}]\right) \times 144.13 \times\right.$ conversion $\left.\%+108.14\right]$.

${ }^{\mathrm{c}}$ Determined by VPO. ${ }^{43}$

d Obtained from GPC analysis and calibrated by polystyrene standard. Values are obtained from GPC times 0.58 .

Table 2. Polymerization of $L$-lactide by copper complex ( $\mathrm{Cu}(\mathrm{MBED}))$ in presence of benzyl alcohol (BnOH).

\begin{tabular}{lccccccr}
\hline & $\begin{array}{c}{[L-\mathrm{LA}]_{0} /} \\
{[\mathrm{Cu}] /[\mathrm{BnOH}]}\end{array}$ & Time $(\mathrm{h})$ & Conversion $^{\mathrm{a}}(\%)$ & $\begin{array}{c}\mathrm{M}_{\mathrm{n}}\left(\mathrm{Theory}^{\mathrm{b}}\right. \\
\left(\mathrm{g} \mathrm{mol}^{-1}\right)\end{array}$ & $\begin{array}{c}\mathrm{M}_{\mathrm{n}}(\mathrm{VPO})^{\mathrm{c}} \\
\left(\mathrm{g} \mathrm{mol}^{-1}\right)\end{array}$ & $\mathrm{M}_{\mathrm{n}}(\mathrm{GPC})^{\mathrm{d}}$ & PDI \\
\hline 1 & $100: 1: 0$ & 24 & $<5$ & $-\mathrm{e}$ & $-\mathrm{e}$ & $-\mathrm{e}$ & $-\mathrm{e}$ \\
2 & $50: 1: 1$ & 24 & 84.0 & 6000 & 8800 & 7800 & 1.11 \\
3 & $100: 1: 1$ & 24 & 93.0 & 13500 & 15800 & 15300 & 1.09 \\
4 & $150: 1: 1$ & 24 & 96.4 & 21000 & 24000 & 23200 & 1.08 \\
5 & $100: 1: 2$ & 20 & 95.3 & 7000 & 8900 & 7800 & 1.07 \\
6 & $100: 1: 4$ & 15 & 97.0 & 3600 & 5100 & 5500 & 1.10 \\
$7^{\mathrm{f}}$ & $150: 1: 1$ & 24 & 92.4 & 20100 & 22900 & 21500 & 1.12 \\
$8^{\mathrm{g}}$ & $150: 1: 1$ & 24 & 94.8 & 20600 & 23000 & 23200 & 1.07 \\
\hline
\end{tabular}

Conditions: $[L-\mathrm{LA}]_{0}=20 \mathrm{mmol}$, room temperature. Solvent: $30 \mathrm{~mL}$ of $\mathrm{CH}_{2} \mathrm{Cl}_{2}$.

a Percentage conversion of the monomer [(weight of polymer recovered/weight of monomer) $\times 100$ ].

${ }^{\mathrm{b}}$ Calculated by $\left[\left([\mathrm{LA}]_{0} /[\mathrm{BnOH}]\right) \times 144.13 \times\right.$ conversion $\left.\%+108.14\right]$.

${ }^{c}$ Determined by VPO. ${ }^{43}$

d Obtained from GPC analysis and calibrated by polystyrene standard. Values are obtained from GPC times 0.58 .

e Data not available.

${ }^{\mathrm{f}}$ For complex Cu-HMBBD.

g For complex Cu-HMBPD. 
All the runs displayed good activities for the polymerization of $L$-lactide and great control of molecular weight, and the presence of benzyl alcohol has a significant influence on the polymerization behavior of the corresponding complexes.

Ring-opening polymerization of $L$-lactide using complex $\mathrm{Cu}$ (MBED), with a monomer to benzyl alcohol ratio $150 / 1$ has been systematically studied at $30^{\circ} \mathrm{C}$ (table 1). It is worth noting that complex $\mathrm{Cu}(\mathrm{MBED})$ is more active in $\mathrm{CH}_{2} \mathrm{Cl}_{2}$ than in toluene or in THF. The difference in activity is probably due to the solubility of complex $\mathrm{Cu}$ (MBED) in $\mathrm{CH}_{2} \mathrm{Cl}_{2}$ which is somewhat higher than that in toluene. The slowest polymerization rate was found in THF probably caused by the coordination ability of THF with copper to retard the reaction rate.

By comparison of the polymerization results listed in table 2, several structure-activity trends may be drawn. Experimental results indicate that compound $\mathrm{Cu}(\mathrm{MBED})$ is an efficient catalyst for ROP of $L$-lactide in the presence of $\mathrm{BnOH}$, when $[\mathrm{M}]_{0} /[\mathrm{I}]_{0}$ ratio is ranging from 50 to 150 . The polymerization is well controlled and the 'living' character is demonstrated by the low polydispersity index (PDI) ranging from 1.08 to 1.11 of the polymers, (table 2 , entry $2-4$ ) and by

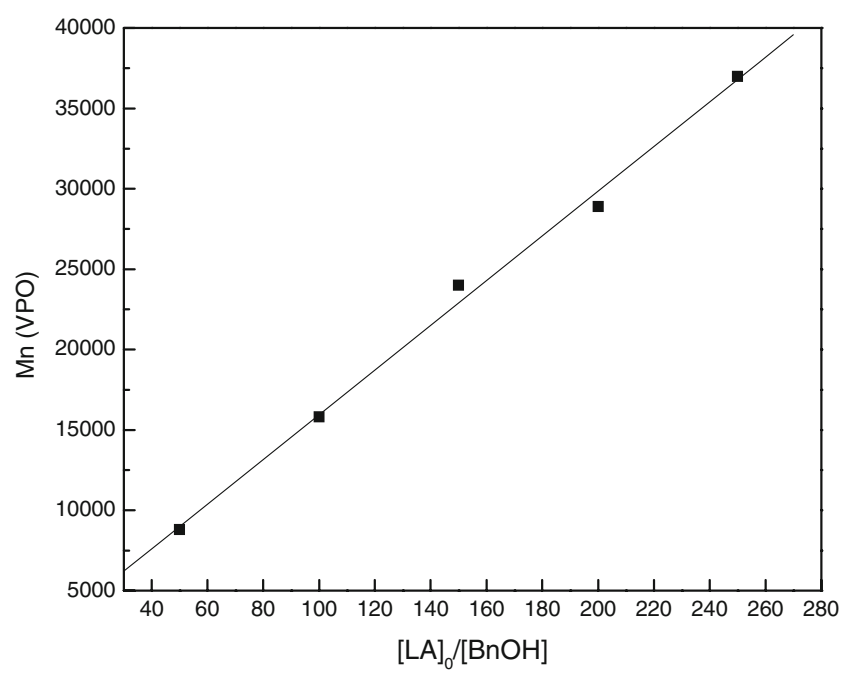

Figure 6. Linear plot of $\mathrm{M}_{\mathrm{n}}$ vs. [Lactide]/[benzyl alcohol] ratio (initial) in the polymerization of $L$-lactide catalyzed by $\mathrm{Cu}(\mathrm{MBED})$ in $\mathrm{CH}_{2} \mathrm{Cl}_{2}$ at room temperature. the linear relationship between $M_{n}$ and $[\mathrm{M}]_{0} /[\mathrm{BnOH}]_{0}$ ratio (figure 6). It is interesting to note that compound $\mathrm{Cu}$ (MBED) catalyzes ROP of $L$-lactide with benzyl alcohol $(\mathrm{BnOH})$ and shows immortality. The 'immortal' character was examined using two or four equiv. ratios of benzyl alcohol as the chain transfer agent (entries 5$6)$. It was found that for polymerization without the use of $\mathrm{BnOH}$, there is almost negligible conversion $(<5 \%)$, (table 2, entry 1) but the use of $\mathrm{BnOH}$ changes drastically the activities of the catalyst. And with higher amount of $\mathrm{BnOH}$ (table 2, entries 5-6), the reaction time decreases from $24 \mathrm{~h}$ to $15 \mathrm{~h}$. This may be due to initiator participating actively in the polymerization reaction. The molecular weight of the polymers was also affected by the amount of $\mathrm{BnOH}$ used. By the addition of two or four equiv. benzyl alcohol in the polymerization reaction, the molecular weight became half or one fourth, respectively. To examine the influence of different diimine bridging parts, a series of copper

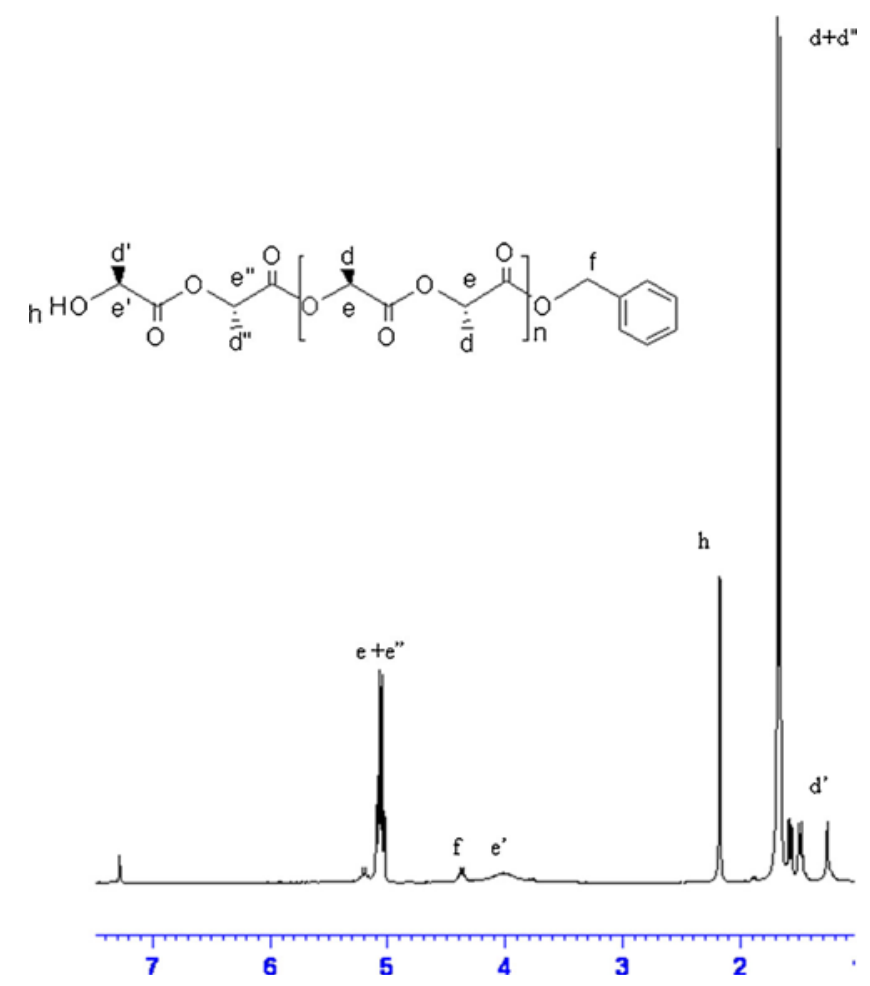

Figure 8. ${ }^{1} \mathrm{H}$ NMR spectrum of PLLA-150 (i.e., $[\mathrm{LA}]_{0} /$ $[\mathrm{BnOH}]=150)$.

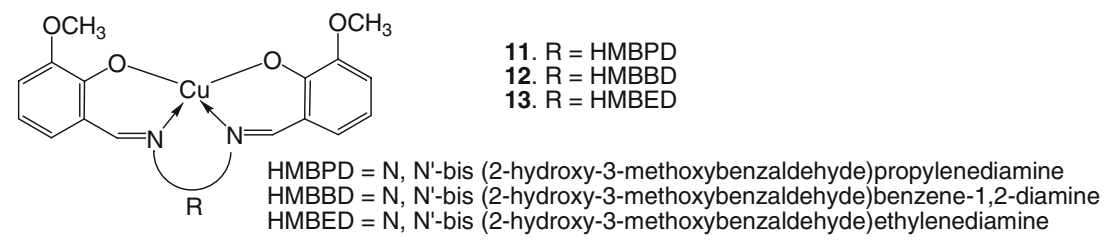

Figure 7. Copper complexes used for ROP of $L$-lactide. 
complexes have been prepared. Among the copper complexes, 11-13 (figure 7) and complex 13 have shown better activity in 24 hours (table 2 , entry $4,7-8$ ). This may be due to creation of more electrophilicity at copper center in comparison to other copper complexes

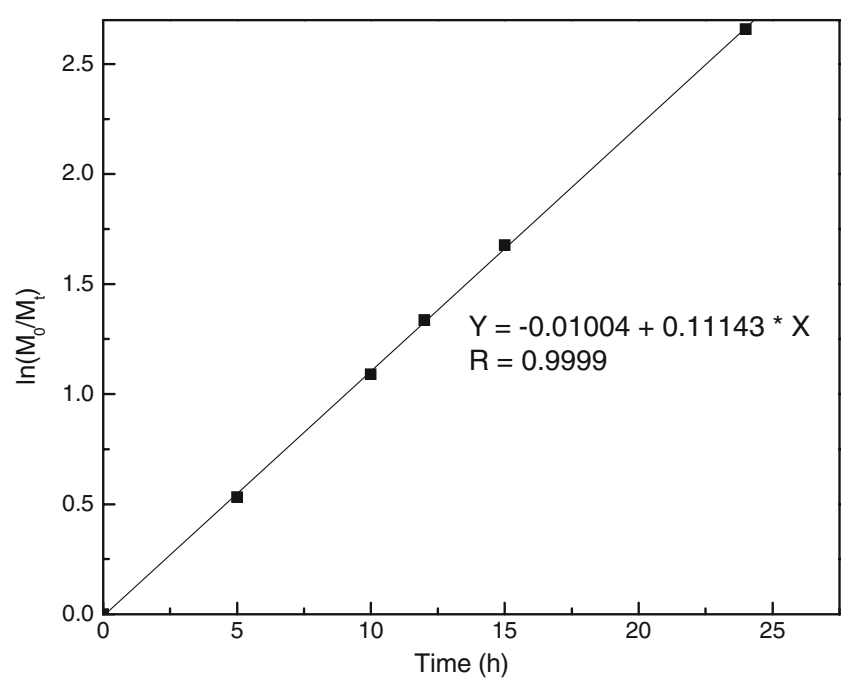

Figure 9. Semilogarithmic plot of $L$-lactide conversion, $\ln \left(\mathrm{M}_{0} / \mathrm{M}_{\mathrm{t}}\right)$ vs. time, catalyzed by $\mathrm{Cu}(\mathrm{MBED})$ in the presence of $\mathrm{BnOH}:[L-\mathrm{LA}]_{0} /[\mathrm{Cu}] /[\mathrm{BnOH}]=100 / 1 / 1$.
11-12 and is favorable for the coordination and insertion of LA monomers. And also, the catalytic activity decreases with the increase of steric hindrance offered by the diamine substituent (table 2 , entry $4,7-8$ ).

To understand the initiating process, ${ }^{1} \mathrm{H}$ NMR studies on the PLLA, catalyzed by $\mathrm{Cu}(\mathrm{MBED})$ with $\mathrm{BnOH}$ as the initiator, were carried out as shown in figure 8 . The ${ }^{1} \mathrm{H}$ NMR spectrum of PLLA-150, prepared from a $[\mathrm{LA}]_{0} /[\mathrm{BnOH}]$ ratio of 150 , indicates that the polymer chain is capped with a benzyl ester group on one end and a hydroxyl group on the other end, suggesting that the initiation occurred through the insertion of the benzyl alkoxy group into $L$-lactide giving an intermediate, which further reacts with an excess of $L$-lactide yielding polyesters. The polymerization procedure agrees with the process found in other metal alkoxides. ${ }^{21-23,29}$ Our polymerization results are much superior to those reported for copper complexes with elaborate ligands. ${ }^{37,38}$ Literature report for the polymerization of $L$-lactide using three different copper phenoxy-ketimine complexes at $160^{\circ} \mathrm{C}$ were found to be, $M_{n}=2200 \mathrm{~g} \mathrm{~mol}^{-1}, M_{n}=4500 \mathrm{~g} \mathrm{~mol}^{-1}$ and $M_{n}=$ $6500 \mathrm{~g} \mathrm{~mol}^{-1},{ }^{37}$ which suggest that our results are superior in terms of $M_{n}$ (table 2). And also, the molecular weights of the polymers obtained in all the entries are

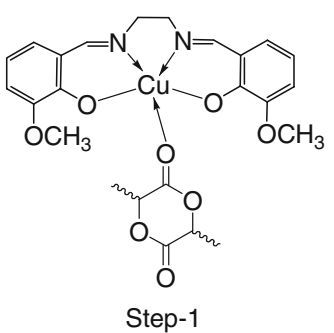
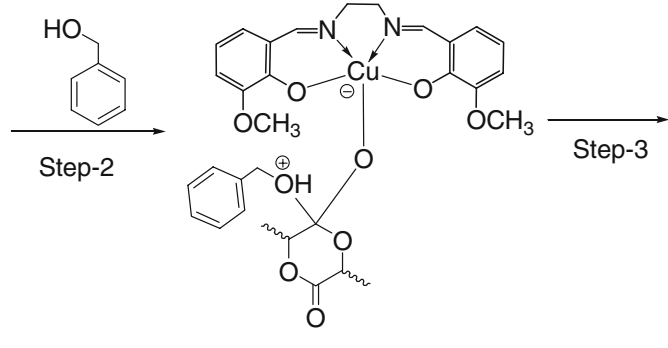

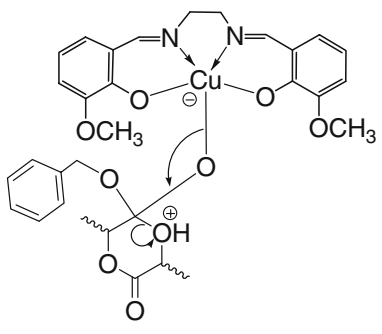<smiles>CC(OCc1ccccc1)C(=O)OC(C)C(=O)OCc1ccccc1</smiles>

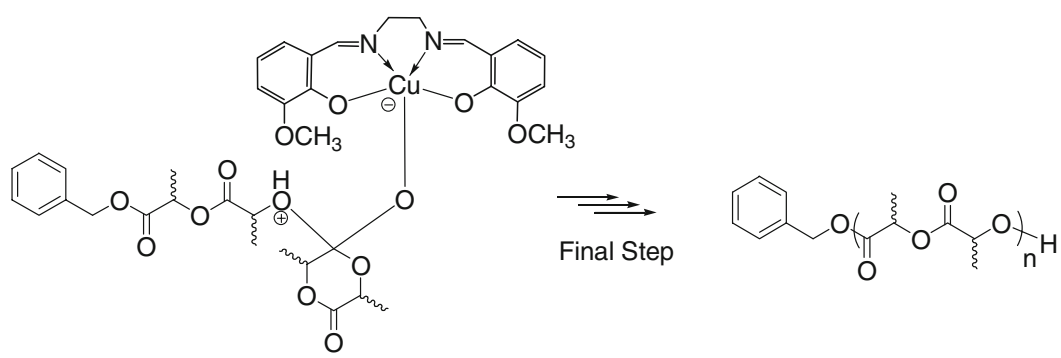

Scheme 3. Reaction steps of ROP of $L$-lactide. 
considerably higher than the molecular weight expected based on the $[\mathrm{LA}] /[\mathrm{BnOH}]$ ratio (table 2 ). This indicates that either propagation is faster than initiation or partial hydrolysis of the initiating functionality has occurred.

\subsection{Kinetics of polymerization}

We have performed kinetic studies for the polymerization of $L$-lactide using $\mathrm{Cu}(\mathrm{MBED}), \mathrm{Cu}-\mathrm{HMBPD}$ and $\mathrm{Cu}-\mathrm{HMBBD}$ as catalysts in the presence of an initiator $\mathrm{BnOH}$ in the ratio $[\mathrm{LA}] \mathrm{o} /[\mathrm{Cu}] /[\mathrm{BnOH}]=100 / 1 / 1$. The results for $\mathrm{Cu}(\mathrm{MBED})$ are depicted in figure 9 and for $\mathrm{Cu}-\mathrm{HMBPD}$ and $\mathrm{Cu}-\mathrm{HMBBD}$ (figures $\mathrm{S} 2$ and $\mathrm{S} 3$ in Supporting Information).

The $\ln [\mathrm{M}]_{\mathrm{o}} /[\mathrm{M}]_{\mathrm{t}}$ vs time plots are linear. These plots imply that the polymerization reaction obeys first order kinetics. The values of the apparent rate constant $\left(\mathrm{k}_{\mathrm{app}}\right)$ may be calculated from the slope of these plots. The value of $k_{\text {app }}$ and standard deviation (SD) for $L$-lactide polymerization in the presence of initiator was found to be $0.11143 \mathrm{~h}^{-1} \& 0.01458 ; 0.11315 \mathrm{~h}^{-1}$ \& 0.08635 and $0.0918 \mathrm{~h}^{-1} \& 0.00665$ for $\mathrm{Cu}(\mathrm{MBED})$, $\mathrm{Cu}(\mathrm{HMPD})$ and $\mathrm{Cu}(\mathrm{HMBD})$ respectively.

\subsection{Mechanism of polymerization}

Considering the experimental findings for the ROP of $L$-lactide, under the conditions mentioned, the polymerization proceeds by the mechanism as outlined in scheme 3. The copper complex (Cu(MBED)) has produced active species in step 2 through fast interactions with lactide and benzyl alcohol. The active species was subsequently used in the formation of intermediates through rearrangements in step 3 and then in step 4, and ring opening of lactide occurs with benzyl ester in one end. Further, another molecule of lactide gets ring opening in step 5 as per step 2. Subsequent additions of lactide produce PLA.

\section{Conclusions}

The copper complex $\mathrm{Cu}(\mathrm{MBED})$ catalyst was shown to be a good catalyst to initiate the ring opening polymerization of $L$-lactide in the presence of benzyl alcohol. The activity of the copper complex $\mathrm{Cu}(\mathrm{MBED})$ is negligible in the absence of benzyl alcohol. Also, in the presence of two or four equivalent benzyl alcohol in the polymerization reactions, the molecular weight became half or one fourth, respectively. All the PLA produced by ROP of $L$-lactide showed moderate molecular weight with conversion rate above $90 \%$. Among the diamine groups, the polymerization rate followed the order as follows: ethylene group $>$ propylene group $>$ benzene group.

\section{Supporting Information (SI)}

FTIR spectra of H2MBED Schiff base (figure S1), semilogarithmic plots of $L$-lactide conversion in time catalyzed by $\mathrm{Cu}-\mathrm{HMBPD}$ (figure $\mathrm{S} 2$ ) and $\mathrm{Cu}-\mathrm{HMBBD}$ (figure S3), FTIR frequencies and electronic transitions of H2MBED Schiff base and its copper complex (table S1) and crystal data of H2MBED and structure refinement parameters (table S2) are given in Supplementary Information, which is available at www.ias.ac. in/chemsci.

\section{Acknowledgments}

The authors are thankful to CSIR and UGC, New Delhi, India for funding. The authors are also grateful to Ravenshaw University and National Institute of Technology, Raipur for providing research facilities.

\section{References}

1. Sutar A K, Maharana T, Dutta S, Chen C-T and Lin C-C 2010 Chem. Soc. Rev. 391724

2. Wu J, Yu T-L, Chen C-T and Lin C-C 2006 Coordin. Chem. Rev. 250602

3. Dechy-Cabaret O, Martin-Vaca B and Bourissou D 2004 Chem. Rev. 1046147

4. Maharana T, Mohanty B and Negi Y S 2009 Prog. Polym. Sci. 2499

5. Uhrich $\mathrm{K}$ E, Cannizzaro $\mathrm{S} \mathrm{M}$, Langer $\mathrm{R} \mathrm{S}$ and Shakesheff K M 1999 Chem. Rev. 993181

6. Jeong B, Bae Y H, Lee D S and Kim S W 1997 Nature 388860

7. Gref R, Minamitake Y, Peracchia M T, Trubetskov V, Torchilin V and Langer R 1994 Science 2631600

8. Langer R 1990 Science 2491527

9. Darensbourg D J, Choi W and Richers C P 2007 Macromolecules $\mathbf{4 0} 3521$

10. Kharas G B, Sanchez-Riora F and Soverson D K 2004 In Polymers of Lactic Acid D P Mobley (Ed.) In Plastics from Microbes (Munchen, Germany: Hanser Publishers)

11. Pilone A, Press K, Goldberg I, Kol M, Mazzeo M and Lamberti M 2014 J. Am. Chem. Soc. 1362940

12. Hancock S L, Mahon M F and Jones M D 2013 Dalton. Trans. 429279

13. Chen H-L, Dutta S, Huang P-Y and Lin C-C 2012 Organometallics 312016

14. Sun Y, Wang L, Yu D, Tang N and Wu J 2014 J. Mol. Catal. A-Chem. 393175

15. Liang Z, Zhang M, Ni X, Li X and Shen Z 2013 Inorg. Chem. Commun. 29145

16. Deana R K, Recklinga A M, Chen H, Dawe L N, Schneider C M and Kozak C M 2013 Dalton. Trans. 42 3504 
17. Gao Y, Dai Z, Zhang J, Ma X, Tang N and Wu J 2014 Inorg. Chem. $\mathbf{5 3} 716$

18. Wojtaszak J, Mierzwicki K, Szafert S, Gulia N and Ejfler J 2014 Dalton. Trans. 432424

19. Chen C-T, Hung C-C, Chang Y-J, Peng K-F and Chen M-T 2013 J. Organomet. Chem. 7381

20. Chuang H-J, Chen H-L, Ye J-L, Chen Z-Y, Huang P-L, Liao T-T, Tsai T-E and Lin C-C 2013 J. Polym. Sci. Pol. Chem. 51696

21. Chisholm M H, Eilerts N W, Huffman J C, Iyer S S, Pacold M and Phomphrai K 2000 J. Am. Chem. Soc. 122 11845

22. Dove A P, Gibson V C, Marshall E L, Rzepa H S, White A J P and Williams D J 2006 J. Am. Chem. Soc. 128 9834

23. Williams C K, Breyfogle L E, Choi S K, Nam W, Young V G, Hillmyer M A and Tolman W B 2003 J. Am. Chem. Soc. 12511350

24. Bnesser A B, Li B and Byers J A 2013 J. Am. Chem. Soc. 13516553

25. Lee E J, Lee K M, Jang J, Kim E, Chung J S, Do Y, Yoon S C and Park S Y 2014 J. Mol. Catal. A-Chem. 38568

26. Sattayanon C, Sontising W, Jitonnom J, Meepowpan P, Punyodom W and Kungwan N 2014 Comput. Theor. Chem. 104429

27. Chen H-Y, Liu M-Y, Sutar A K and Lin C-C 2010 Inorg. Chem. 49665

28. Tsai C-Y, Du H-C, Chang J-C, Huang B-H, Ko B-T and Lin C-C 2014 RSC Adv. 414527

29. Petrus R and Sobota P 2012 Organometallics 31 4755
30. Chen H-Y, Peng Y-L, Huang T-H, Sutar A K, Miller S A and Lin C-C 2011 J. Mol. Catal. A-Chem. 33961

31. Mou Z, Liu B, Wang M, Xie H, Li P, Li L, Li S and Cui D 2014 Chem. Commun. 5011411

32. Abbina S and Du G 2014 ACS Macro. Lett. 3689

33. Fliedel C, Vila-Viçosa D, Calhorda M J, Dagorne S and Aviles T 2014 Chem. Cat. Chem. 61357

34. Piao L, Deng M, Chen X, Jiang L and Jing X 2003 Polymer 442331

35. (a) Sutar A K, Maharana T, Das Y and Rath P 2014 J. Chem. Sci. 126 1695; (b) Gupta K C and Sutar A K 2008 Coordin. Chem. Rev. 252 1420; (c) Meena J S and Thankachan P P 2014 J. Chem. Sci. 126691

36. Appavoo D, Omondi B, Guzei I A, Wyk J L V, Zinyemba O and Darkw J 2014 Polyhedron 6955

37. John A, Katiyar V, Pang K, Shaikh M M, Nanavati H and Ghosh P 2007 Polyhedron 264033

38. Bhunora S, Mugo J, Bhaw-Luximon A, Mapolie S, Wyk J V, Darkwa J and Nordlander E 2011 Appl. Organomet. Chem. 25133

39. Whitehorne T J J and Schaper F 2013 Inorg. Chem. 52 13612

40. Gowda R R and Chakraborty D 2011 J. Mol. Catal. A-Chem. 34986

41. (a) Grivani G and Akherati A 2013 Inorg. Chem. Commun. 28 90; (b) Sutar A K, Das Y, Pattnaik S, Routaray A, Nath N, Rath P and Maharana T 2014 Chin. J. Catal. 351701

42. Fraile J M, Mayoral J A, Royo A J, Salvador R V, Altava B, Luis S V and Burguete M I 1996 Tetrahedron 529853

43. Alamri H, Zhao J, Pahovnik D and Hadjichristidis N 2014 Polym. Chem. 55471 